\title{
Phenolic Compounds and Antioxidant Properties of Field-Grown and In Vitro Leaves, and Calluses in Blackberry and Blueberry
}

\author{
Tijana Kolarević ${ }^{1,+}$ D , Danijel D. Milinčić ${ }^{1,+}$, Tatjana Vujović ${ }^{2}$, Uroš M. Gašić ${ }^{3}$ (D) Ljiljana Prokić ${ }^{4}$ (D), \\ Aleksandar Ž. Kostić ${ }^{1}$ (D), Radosav Cerović ${ }^{5}$, Sladjana P. Stanojevic ${ }^{1} \mathbb{D}$, Živoslav Lj. Tešić ${ }^{6}$ \\ and Mirjana B. Pešić $1, * \mathbb{D}$
}

Citation: Kolarević, T.; Milinčić, D.D.; Vujović, T.; Gašić, U.M.; Prokić, L.; Kostić, A.Ž.; Cerović, R.;

Stanojevic, S.P.; Tešić, Ž.L.; Pešić, M.B. Phenolic Compounds and

Antioxidant Properties of

Field-Grown and In Vitro Leaves, and Calluses in Blackberry and Blueberry. Horticulturae 2021, 7, 420. https:// doi.org/10.3390/horticulturae7110420

Academic Editor:

Alessandra Francini

Received: 31 August 2021

Accepted: 8 October 2021

Published: 20 October 2021

Publisher's Note: MDPI stays neutral with regard to jurisdictional claims in published maps and institutional affiliations.

Copyright: (C) 2021 by the authors. Licensee MDPI, Basel, Switzerland. This article is an open access article distributed under the terms and conditions of the Creative Commons Attribution (CC BY) license (https:/ / creativecommons.org/licenses/by/ $4.0 /)$.
1 Faculty of Agriculture, University of Belgrade, Nemanjina 6, Zemun, 11080 Belgrade, Serbia; tijana.curic23@gmail.com (T.K.); danijel.milincic@agrif.bg.ac.rs (D.D.M.); akostic@agrif.bg.ac.rs (A.Ž.K.); sladjas@agrif.bg.ac.rs (S.P.S.)

2 Fruit Research Institute, Kralja Petra I No. 9, 32000 Čačak, Serbia; tvujovic@institut-cacak.org

3 Department of Plant Physiology, National Institute of Republic of Serbia, Institute for Biological Research "Siniša Stanković", University of Belgrade, Bulevar Despota Stefana 142, 11060 Belgrade, Serbia; uros.gasic@ibiss.bg.ac.rs

4 Chair of Agrochemistry and Plant Physiology, Faculty of Agriculture, University of Belgrade, Nemanjina 6, Zemun, 11080 Belgrade, Serbia; ljprokic@agrif.bg.ac.rs

5 Innovation Center, Faculty of Technology and Metallurgy, University of Belgrade, Karnegijeva 4, 11000 Belgrade, Serbia; radosav.cerovic@gmail.com

6 Chair of Analytical Chemistry, Faculty of Chemistry, Studentski Trg 12-16, 11000 Belgrade, Serbia; ztesic@chem.bg.ac.rs

* Correspondence: mpesic@agrif.bg.ac.rs

+ These authors equally contributed to the work.

Abstract: The aim of this study was to evaluate the content and profile of the phenolic compounds (PCs) and antioxidant properties of field-grown leaves, in vitro leaves and in vitro callus cultures of the blackberry 'Čačanska Bestrna' and blueberry 'Toro'. In vitro shoots of the selected genotypes were grown either on original Murashige and Skoog (MS) medium containing $1 \mathrm{mg} / \mathrm{L} \mathrm{BA}, 0.1 \mathrm{mg} / \mathrm{L} \mathrm{IBA}$ and $0.1 \mathrm{mg} / \mathrm{L} \mathrm{GA}_{3}$ ('Čačanska Bestrna') or on MS medium with macroelements reduced to $1 / 2$, $2 \mathrm{mg} / \mathrm{L}$ zeatin and $0.2 \mathrm{mg} / \mathrm{L}$ IAA ('Toro'). Callus cultures were induced from in vitro leaves and established on MS medium with $2 \mathrm{mg} / \mathrm{L} \mathrm{BA}$ and $2 \mathrm{mg} / \mathrm{L}$ 2,4-D ('Čačanska Bestrna') or MS medium with half strength macroelements, $2 \mathrm{mg} / \mathrm{L} \mathrm{BA}, 2 \mathrm{mg} / \mathrm{L} \mathrm{2,4-D}$ and $1 \mathrm{mg} / \mathrm{L}$ NAA ('Toro'). Total phenolic (TPC) and flavonoid content (TFC) were the highest in blueberry leaves, whereas low TPC and TFC values were obtained in callus cultures of both cultivars. A higher content of PCs in blueberry leaves compared to blackberry leaves was determined by the UHPLC-DAD MS/MS technique. Quercetin derivatives and phenolic acids were the dominant PCs in the leaves of both berries, whereas gallocatechin was present in a significant amount in blueberry leaves. Callus cultures of both berries had a specific PC profile, with none detected in the leaves except quercetin-3$\mathrm{O}$-glucoside and quercetin-3-O-rutinoside. Blackberry leaves showed the best antioxidant properties as estimated by ferric reducing power (FRP), ABTS $\bullet+$ and $\mathrm{DPPH}^{\bullet}$ scavenging activity assays. Callus cultures of both berries exhibited three to five times lower ABTS $\bullet+$ and ten to seventeen times lower $\mathrm{DPPH}^{\bullet}$ scavenging activity compared to corresponding leaves. The analyzed leaves and callus cultures can be a good source of PCs with good antioxidant properties and specific phenolics, respectively, for applications in the food and pharmaceutical industries.

Keywords: open-field plants; tissue culture plants; in vitro callus culture; Rubus subg. Rubus Watson; Vaccinium corymbosum L.; phenolics; radical scavenging activities; ferric reducing power 


\section{Introduction}

Blueberry and blackberry have high economic importance, particularly in hilly and mountainous regions of Serbia. The special economic importance of these fruit species is determined by the high usage value of their fruits, the profitability of production, high margins, contribution to additional employment, and more [1]. Furthermore, the small edible and colored berries of genera Vaccinium and Rubus are recognized as a good source of bioactive compounds (BCs), primarily phenolics, which contribute to the berries' organoleptic properties and after consumption exert a positive impact on human health [2,3]. In addition to their highly valuable fruits, the leaves of berry plants are also a rich source of phenolics and are often used in traditional medicine to treat numerous diseases such as colds, various inflammations, diabetes [4]. Leaves are present as a byproduct of growing berries and can be used as an alternative source of bioactive compounds which can be applied further for the development of functional food products and nutraceuticals [4-6]. Moreover, the European Medicines Agency (EMA) has approved the marketing and use of some Rubus leaf extracts and infusions for medical purposes [4]. Due to the mentioned characteristics of both fruits and leaves there has been increasing interest in growing berries in recent years, with a special emphasis on blueberries and blackberries. Furthermore, there is great interest in evaluating the BC composition of berry leaves, in vitro screening of their antioxidant and antimicrobial properties, and evaluation of in vivo biological activities and conduction of clinical trials [5-11]. For example, the highest values of antioxidant properties evaluated with $\mathrm{DPPH}^{\bullet}$ and $\mathrm{ABTS}^{\bullet+}$ scavenging or FRAP assays were $586.6 \mu \mathrm{mol}$ TEAC/g DW, $862.4 \mu \mathrm{mol} \mathrm{TEAC/g}$ DW and $2674 \mu \mathrm{mol}$ FEAC/g DW for 'Nanjin' variety among the 73 investigated blueberry cultivars [11]; that is, $45.0,257$, and $139 \mathrm{mg} / \mathrm{g}$ DW for leaves of 'Bluerain' and 'Vernon' varieties among 104 selected blueberry cultivars [12], respectively. On the other hand, some wild blackberry cultivars showed high ABTS ${ }^{\bullet+}$ scavenging activity (212.69 mmol TE/g dm) and FRAP (192.91 mmol TE/g dm), as well as high correlations with total phenolic content and content of ellagitannins [9]. Leaf extracts of six commercial blueberry varieties [6] and Vaccinium corymbosum variety [13] showed good antimicrobial properties (MIC and $\mathrm{MBC}$ ) against some gram negative and gram-positive bacteria strains. Thus far, the phenolic profiles, antioxidant and antimicrobial properties of field-grown leaves of different blueberry and blackberry cultivars, in particular, 'Toro' $[6,11]$ and 'Čačanska Bestrna' [5], have been successfully evaluated. More precisely, the DPPH' scavenging activity of blackberry ('Čačanska Bestrna') and blueberry ('Toro') leaves were 83.77\% [5] and $305.0 \mu \mathrm{mol}$ TEAC/g DW [11]. In addition, extracts of the leaves of Toro blueberry cultivar have shown good antibacterial potential against some bacterial strains such as Staphylococcus aureus, Rhodococcus equi, K. pneumonia and E. fecalis [6]. Furthermore, the extract of 'Toro' blueberry showed a good antimutagenic effect against different Salmonella typhimurium strains, with percent inhibitions of $32.98 \%$ (TA98) and $38.68 \%$ (TA100), which gives them the possibility of potential application as a safe and useful alternative for the prevention of mutations [6].

However, the use of highly valuable leaves from field-grown berry plants is often limited due to the frequent use of pesticides [14], as well as their seasonal availability. This is why there is growing interest in and questions about the potential propagation and growing of berry plants in vitro as a source of secondary metabolites, or the induction of callus cultures using a specific nutrient medium for targeted production of some BCs which have significant potential as antioxidants [15-18].

Several methods are available in plant tissue culture, among which organogenesis and callogenesis are the most commonly used [15]. Organogenesis involves the production of plant organs (shoots or roots), directly from meristems or indirectly from dedifferentiated cells which are known as callus [15]. The obtained in vitro plant cultures can be used as a sustainable and alternative source of valuable BCs, primarily phenolic compounds, which have potential application as food additives [17]. Some blueberry and blackberry cultivars have been successfully micropropagated via axillary shoot culture and through indirect shoot organogenesis [19-23]. However, according to our knowledge, the pheno- 
lic profile and antioxidant properties of blueberry and blackberry leaves obtained from in vitro shoots grown on specific nutrient medium have not yet been examined. On the other hand, callogenesis creates an amorphous cell mass in response to the exposure of explants to various biotic and abiotic elicitors which further initiate or enhance the biosynthesis of specific BCs $[15,24]$. The produced calluses can be used for plant regeneration or for targeted production of important metabolites in the cell suspension $[15,16,18]$. The biosynthesis of phenolic compounds in plant calluses depends on numerous factors such as nutrient media, plant growth regulators (PGRs), precursor feeding and elicitors [17]. Plant callus/cell cultures have the ability to accumulate secondary metabolites, which is a very promising system for biotechnological production of specific phenolic compounds [16]. For example, callus culture of Vitis vinifera has shown promising potential for the production of phenolic compounds [25] or specific phenolic classes such as anthocyanins [26], resveratrol [27] or stilbenes [28]. Moreover, phenolic compounds from the callus culture of different grape varieties have been successfully used to enrich food products such as yogurt [29]. Furthermore, callus cultures of different blueberry [30,31], and blackberry [20] cultivars have already been successfully created. The antioxidant properties and total phenolic content of blackberry calluses [20], that is, the phenolic profile of some varieties of blackberry calluses [31], were determined, as a prerequisite for further biotechnological production of highly valuable active compounds. However, according to our knowledge, calluses of blueberry 'Toro' and blackberry 'Čačanska Bestrna' have not yet been produced and analyzed. Furthermore, the antioxidant properties of in vitro leaves and calluses of these two berry cultivars were not determined by FRP, $\mathrm{ABTS}^{\bullet+}$ and $\mathrm{DPPH}^{\bullet}$ scavenging activity assays until now.

Therefore, the aim of this study was to evaluate and to compare the content and profile of phenolic compounds of field-grown and in vitro leaves and callus cultures of blackberry 'Čačanska Bestrna' and blueberry 'Toro', as well as their antioxidant properties, using three common antioxidant assays: FRP, $\mathrm{ABTS}^{\bullet+}$ and $\mathrm{DPPH}^{\bullet}$ scavenging activities. Bearing in mind a number of advantages of the plant tissue culture-based production of secondary metabolites in comparison with conventional agricultural production, including controlled production via standardized protocols independent from seasonal variation, low water and carbon input, no use of pesticide and herbicides, etc. [32], and given the economic importance of these fruit species and their potential for targeted BC production, the results could help to estimate their possible use in the food and pharmaceutical industry.

\section{Materials and Methods}

\subsection{Plant Materials}

Research was conducted using blackberry cultivar ‘Čačanska Bestrna' (Rubus subg. Rubus Watson) and blueberry cultivar 'Toro' (Vaccinium corymbosum L.). 'Čačanska Bestrna' is a cultivar developed at the Fruit Research Institute, Čačak, which has been widely planted in Serbia; it displays excellent performance regarding cropping, fruit quality and resistance to diseases. In the group of semi-erect thornless blackberry cultivars, this cultivar reaches about $10 \%$ of the total world production. Although not widely grown in Serbia, 'Toro' belongs to the most common mid-season highbush blueberry cultivars in Central and Eastern European countries [33] and represents a self-fertile and heavy producer with large, juicy, sweet, and never tart berries. In addition to berries, the leaves of both cultivars appear to be good sources of antioxidants and have strong antibacterial activity $[4,5]$.

Field-grown leaves as well as in vitro leaves and callus cultures of the two berry plant genotypes were obtained from the Fruit Research Institute, Čačak, Serbia. In vitro shoots and calluses were cultivated on nutrient media in a growth room at $23 \pm 1{ }^{\circ} \mathrm{C}$, under $16 \mathrm{~h}$-photoperiod and light intensity of $8.83 \mathrm{~W} / \mathrm{m}^{2}$, using white fluorescent tubes $(6500 \mathrm{~K}$, $40 \mathrm{~W}$ ) (Tissue Culture Laboratory of Fruit Research Institute), while field-grown leaves were obtained from plants grown in the Institute's research fields. 


\subsection{In Vitro Shoot Cultivation and Callus Induction from Leaves}

Field grown plants of both cultivars were used as the source of initial explants for in vitro culture. Aseptic culture was established using single-node cuttings of newly formed shoots taken from branches during the spring. Cuttings with axillary buds were submerged in lukewarm water with a few drops of Tween 20 for $30 \mathrm{~min}$ and washed under running tap water for $2 \mathrm{~h}$, followed by sterilization in $70 \%$ ethanol $(1 \mathrm{~min})$ and in a solution containing $0.1 \% \mathrm{HgCl}_{2}$ and $0.01 \%$ Tween $20(5 \mathrm{~min})$, and finally washed with sterile distilled water $(3 \times 5 \mathrm{~min})$ to remove all traces of disinfectants.

After establishment of aseptic cultures, shoots of examined genotypes were grown and multiplied on original or partially modified Murashige and Skoog (MS) medium [34], (Table S1). The axillary shoot proliferation of blackberry 'Čačanska Bestrna' and blueberry 'Toro' are presented in Figures S1 and S2. Composition of the media used for in vitro shoot multiplication of berry plant genotypes are listed in Table 1.

Table 1. Composition of media used for micropropagation of blackberry and blueberry.

\begin{tabular}{|c|c|c|c|c|c|c|c|}
\hline Genotype & $\begin{array}{c}\text { Macro- } \\
\text { Elements }\end{array}$ & $\begin{array}{c}\text { Micro- } \\
\text { Elements }\end{array}$ & Vitam. & $\begin{array}{c}\text { Plant Growth Regulators } \\
\text { (PGRs) }\end{array}$ & Sucrose & Agar & $\mathrm{pH}$ \\
\hline $\begin{array}{c}\text { Blackberry } \\
\text { ‘Čačanska Bestrna' }\end{array}$ & MS & MS & MS & $\begin{array}{l}\text { 6-Benzylaminopurine }(1 \mathrm{mg} / \mathrm{L}) \\
\text { Indole-3-butyric acid }(0.1 \mathrm{mg} / \mathrm{L}) \\
\text { Gibberellic acid }(0.1 \mathrm{mg} / \mathrm{L})\end{array}$ & $20 \mathrm{~g} / \mathrm{L}$ & $7 \mathrm{~g} / \mathrm{L}$ & $5.7-5.8$ \\
\hline $\begin{array}{l}\text { Blueberry } \\
\text { 'Toro' }\end{array}$ & MS $1 / 2$ & MS & MS & $\begin{array}{c}\text { Zeatin }(2 \mathrm{mg} / \mathrm{L}) \\
\text { Indole-3-acetic acid }(0.2 \mathrm{mg} / \mathrm{L})\end{array}$ & $20 \mathrm{~g} / \mathrm{L}$ & $7 \mathrm{~g} / \mathrm{L}$ & 4.5 \\
\hline
\end{tabular}

MS-Murashige and Skoog basal medium.

Both blackberry and blueberry callus cultures were induced from in vitro leaves. Leaves were collected from the upper third of in vitro propagated shoots, cut three times transversely across the mid-vein and placed with the adaxial surface touching regeneration medium poured into Petri dishes $(9 \mathrm{~cm}$ in diameter, around $50 \mathrm{~mL}$ of medium). The ingredients of media used for induction and maintaining of callus cultures are presented in Table 2.

Table 2. Composition of media used for callus induction.

\begin{tabular}{|c|c|c|c|c|c|c|c|}
\hline Genotype & $\begin{array}{l}\text { Macro- } \\
\text { Elements }\end{array}$ & $\begin{array}{c}\text { Micro- } \\
\text { Elements }\end{array}$ & Vitam. & Plant Growth Regulators (PGRs) & Sucrose & Agar & $\mathrm{pH}$ \\
\hline $\begin{array}{c}\text { Blackberry } \\
\text { 'Čačanska Bestrna' }\end{array}$ & MS & MS & MS & $\begin{array}{c}\text { 6-Benzylaminopurine (2 mg/L) } \\
\text { 2,4-dichlorophenoxyacetic acid ( } 2 \mathrm{mg} / \mathrm{L})\end{array}$ & $30 \mathrm{~g} / \mathrm{L}$ & $7 \mathrm{~g} / \mathrm{L}$ & $5.7-5.8$ \\
\hline $\begin{array}{l}\text { Blueberry } \\
\text { 'Toro' }\end{array}$ & MS $1 / 2$ & MS & MS & $\begin{array}{c}\text { 6-Benzylaminopurine }(2 \mathrm{mg} / \mathrm{L}) \\
\text { 2,4-dichlorophenoxyacetic acid }(2 \mathrm{mg} / \mathrm{L}) \\
\alpha \text {-Naphthaleneacetic acid }(1 \mathrm{mg} / \mathrm{L})\end{array}$ & $30 \mathrm{~g} / \mathrm{L}$ & $7 \mathrm{~g} / \mathrm{L}$ & 4.5 \\
\hline
\end{tabular}

MS-Murashige and Skoog basal medium.

In vitro shoot and callus cultures of blackberry 'Čačanska Bestrna' and blueberry 'Toro' are presented in Figure 1.

Field-grown and in vitro young and newly formed leaves of berry plants as well as their callus cultures were used for further phenolic characterization and the evaluation of antioxidant properties. 

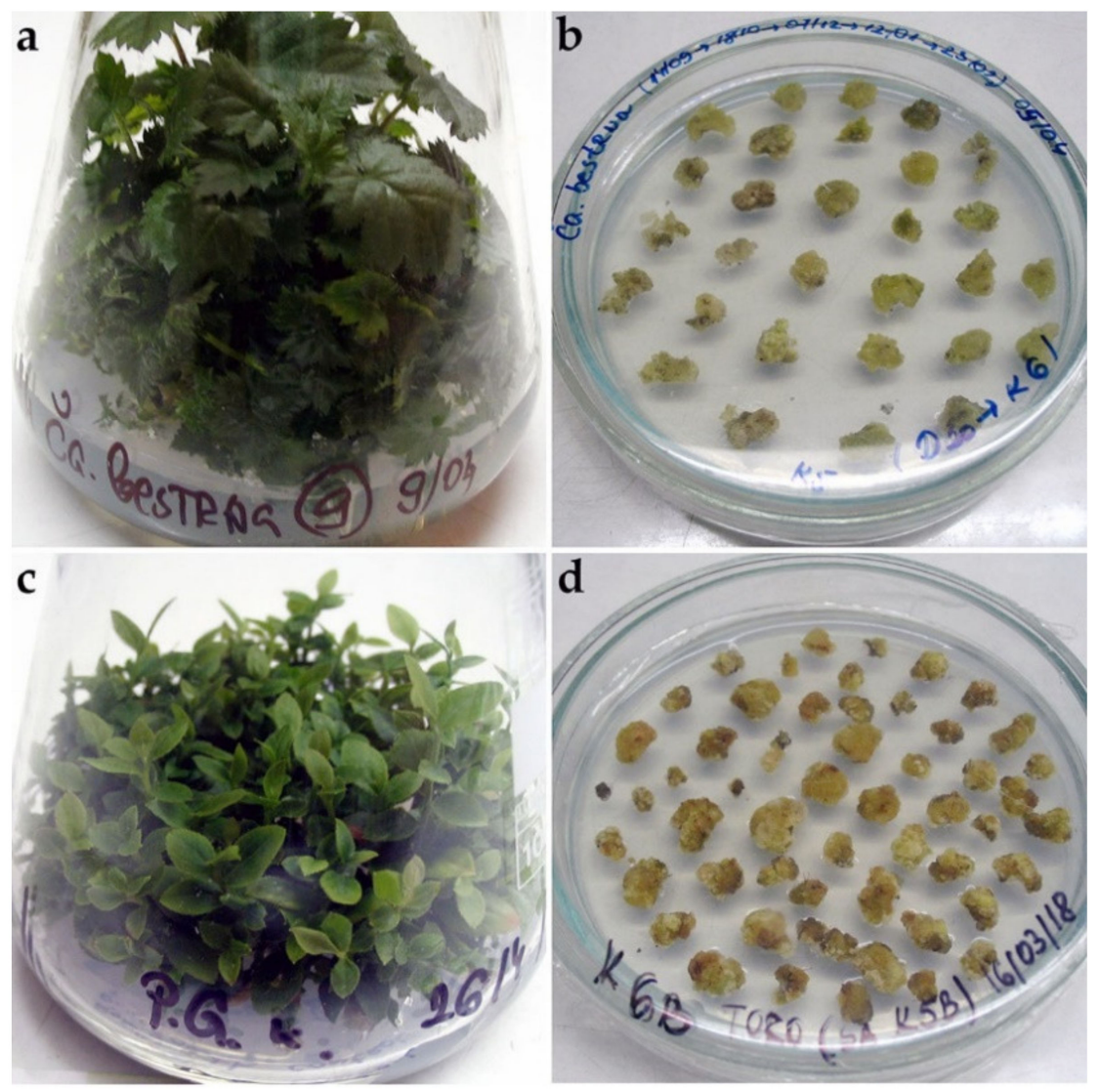

Figure 1. In vitro shoot and callus cultures of blackberry 'Čačanska Bestrna' (a,b) and blueberry 'Toro' (c,d).

\subsection{Preparation of Leaves and Callus Culture Extracts}

Collected samples of leaves and calluses were finely ground and homogenized with liquid nitrogen using an Ika A11 basic mill. The extracts were then prepared using the extraction protocol previously described by Pavlović et al. [35], with slight modifications. Briefly, previously ground samples $(1 \mathrm{~g}$ ) were extracted using $80 \%$ methanol with $0.1 \% \mathrm{HCl}$ on a mechanical stirrer (Mechanical stirrer Thys 2 ) for $1 \mathrm{~h}$. After that, the samples were centrifuged for 10 min at $4000 \times g$ (Janetzki T32c, Wallhausen, Germany) and filtered through Whatman No. 1 filter paper. The extraction procedure was repeated twice and supernatants were collected. Furthermore, combined supernatants were evaporated using a rotary evaporator to dryness $\left(40^{\circ} \mathrm{C}\right)$ (Laborota 4000 , Heidolph Instruments, Schwabach, Germany) and reconstituted in $10 \mathrm{~mL}$ miliQ water for further analysis. The suspensions were filtrated through $0.45 \mu \mathrm{m}$ syringe filters before further spectrophotometric and UHPLC-DAD MS/MS analysis. These extracts represented aqueous extracts of samples.

\subsection{Total Phenolic and Flavonoid Content}

Total phenolic and flavonoid content in the blueberry/blackberry leaves and calluses were determined using a colorimetric assay with Folin-Ciocalteu's reagent [36]; that is, assay with aluminium chloride [37]. Absorbance was measured at $765 \mathrm{~nm}$ for TPC and $510 \mathrm{~nm}$ for TFC, using a Shimadzu UV-1800 spectrophotometer (Shimadzu USA Manufacturing, Inc., Canby, OR, USA). Results for TPC were expressed in mg of gallic acid equivalent (mg GAE/g DW), while results for TFC were expressed as catechin equivalents (mg CE/g DW), both per g dry weight of samples. 


\subsection{UHPLC-DAD MS/MS Analysis of Leaves and Calluses}

The identification and quantification of phenolic compounds in leaves and calluses of 'Toro' and 'Čačanska Bestrna' was conducted using a Dionex Ultimate 3000 UHPLC system equipped with diode array detector (DAD) and TSQ Quantum Access Max triplequadrupole mass spectrometer (MS) (ThermoFisher Scientific, Basel, Switzerland), as previously detailed by Pešić et al. [37]. A Syncronis C18 column $(100 \times 2.1 \mathrm{~mm}, 1.7 \mathrm{~mm}$ particle size) from Thermo Fisher Scientific was used as the analytical column for separation. The mass spectrometry data were acquired in the negative ion mode, in the $\mathrm{m} / \mathrm{z}$ range from 100 to 1000. Full scanning and product ion scanning (PIS) were conducted for the qualitative analysis of the targeted phenolic compounds. The collision-induced dissociation experiments were performed using argon as the collision gas, and the collision energy varied depending on the compound. The time-selected reaction monitoring experiments for quantitative analysis were performed using two $\mathrm{MS}^{2}$ fragments for each compound that was previously defined as dominant in the PIS experiments (Table S2). Other chromatographic and MS settings were the same as in Pešić et al. [37]. However, it should be noted that in this study only MS data of commercially available standards were used for both identification and quantification of PCs. The Xcalibur software (version 2.2) was used for instrument control as well as for the acquisition and analysis of data. Calculation of the concentrations was based on the external standard method. Standards of phenolic compounds (gallic acid, vanillic acid, ferulic acid, syringic acid, chlorogenic acid, catechin, catechin gallate, gallocatechin, quercetin, quercetin-3-O-rutinoside, quercetin3-O-glucoside, quercetin-3-O-rhamnoside, isohramnetin-3-O-rutinoside, isohramnetin-3$\mathrm{O}$-glucoside, kaempferol-3-O-glucoside, kaempferol, apigenin-7-O-glucoside, naringenin, aesculetin, and phlorizin) were obtained from Sigma Aldrich (Steinheim, Germany). The total amounts of each identified compound were evaluated via calculation of the peak areas and expressed as $\mathrm{mg} / \mathrm{kg}$ dry weight (DW) of the sample.

\subsection{Antioxidant Properties}

\subsubsection{Ferric Reducing Power (FRP)}

The ferric reducing power of leaves and callus extracts was determined according to the method previously described by Pešić et al. [37], with slight modifications. Briefly, an aliquot of the appropriately diluted sample $(2.5 \mathrm{~mL})$ was mixed with $2.5 \mathrm{~mL}$ of $0.2 \mathrm{M}$ phosphate buffer $(\mathrm{pH}=6.6)$ and $2.5 \mathrm{~mL}$ of $1 \%$ potassium ferricyanide. Then, the homogenized mixture was incubated at $50{ }^{\circ} \mathrm{C}$, and after $20 \mathrm{~min}$ it was mixed with $2.5 \mathrm{~mL}$ of $10 \%$ TCA. Supernatant collected after centrifugation $(2.5 \mathrm{~mL})$ was mixed with $2.5 \mathrm{~mL}$ of milliQ water and $0.5 \mathrm{~mL}$ of $0.1 \%$ ferric chloride. After $10 \mathrm{~min}$, the absorbance of the mixture was measured at $700 \mathrm{~nm}$. Results for FRP were expressed as $\mathrm{mg}$ gallic acid equivalents per $\mathrm{g}$ dry weight of the sample.

\subsection{2. $\mathrm{ABTS}^{\bullet+}$ and $\mathrm{DPPH}^{\bullet}$ Radical Scavenging Activity}

$\mathrm{ABTS}^{\bullet+}$ scavenging activity was evaluated as previously reported by Pešić et al. [37]. Prepared ABTS ${ }^{\bullet}$ working solution $(1 \mathrm{~mL})$ was mixed with the sample $(10 \mu \mathrm{L})$ and left in the dark for $7 \mathrm{~min}$. Afterwards, the absorbance of the mixture was measured at $734 \mathrm{~nm}$.

$\mathrm{DPPH}^{\bullet}$ scavenging activity was performed according to a method previously reported by Gawron-Gzella et al. [38], with small modifications. Briefly, $120 \mu \mathrm{L}$ of prepared $150 \mu \mathrm{M}$ $\mathrm{DPPH}^{\bullet}$ working solution was mixed with $15 \mu \mathrm{L}$ of the sample and incubated for $30 \mathrm{~min}$ in the dark. Next, the absorbance was measured at $515 \mathrm{~nm}$ using a Plate Reader (Tecan Sunrise Spectrophotometer, Tecan Trading AG, Switzerland).

The percentage of $\mathrm{ABTS}^{\bullet}$ and $\mathrm{DPPH}^{\bullet}$ quenched radicals was calculated using the following Equation (1): 
where Ac is control absorbance $\left(\mathrm{ABTS}^{\bullet}{ }^{ \pm}\right.$or $\mathrm{DPPH}^{\bullet}$ working solution mixed with $10 \mu \mathrm{L}$ of methanol) and As is absorbance of the sample mixed with $\mathrm{ABTS}^{\bullet+}$ or $\mathrm{DPPH}^{\bullet}$ working solution.

The ABTS $\bullet+$ scavenging activity was expressed as $\mu \mathrm{g}$ of ascorbic acid equivalents per $\mathrm{mL}$ of sample ( $\mu \mathrm{g} \mathrm{AAE} / \mathrm{mL}$ ).

\subsection{Statistical Analysis}

All of the results were performed in triplicate and presented as the mean values \pm standard deviation (SD). Data for TPC, TFC and antioxidant properties were analyzed using Two-way ANOVA considering the origin of the samples (field-grown leaves, in vitro leaves and callus cultures) and berry plant cultivars as fixed effects and the replicates as a random effect. Significant differences $(p<0.05)$ between means were determined by Tukey's test, using GraphPad Prism6 software (USA). Significant differences $(p<0.05)$ between the means for individual phenolics were determined by Student's $t$-test. The correlation analyses were performed by calculating Pearson's correlation coefficient $(r)$, $(p<0.05)$, using the Statistica software version 12.0 (StatSoft Co., Tulsa, OK, USA). Figures were drawn using GraphPad Prism6 software (USA).

\section{Results and Discussion}

\subsection{Total Phenolic and Flavonoid Content}

The TPC of aqueous extracts of blueberry and blackberry leaves and calluses are presented in Figure 2a.

(a)

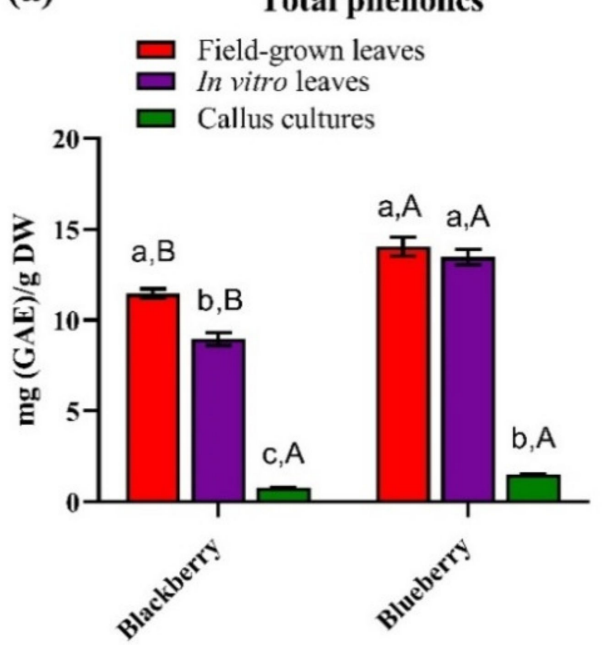

(b) Total flavonoid content

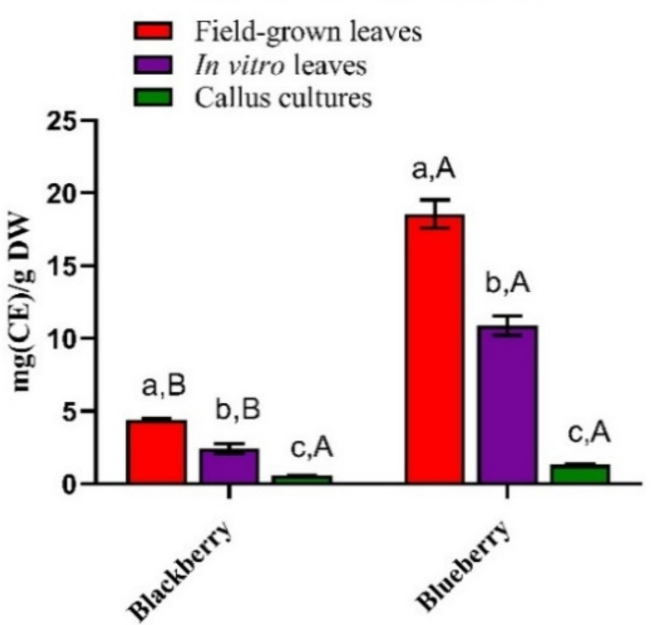

Figure 2. (a) Total phenolic content and (b) Total flavonoid content of blackberry 'Čačanska Bestrna' and blueberry 'Toro' leaves and callus samples. The bars with $( \pm)$ standard deviation represent mean values. The different lowercase letters indicate a significant difference $(p<0.05)$ between field-grown leaves, in vitro leaves and callus culture of the same berry; different uppercase letters indicate a significant difference $(p<0.05)$ between the same type of samples of two different berry cultivars.

The TPC of aqueous extracts of field-grown and in vitro leaves of 'Toro' blueberry were $14.06 \pm 0.51$ and $13.47 \pm 0.42 \mathrm{mg} \mathrm{GAE} / \mathrm{g} \mathrm{DW}$, without a statistically significant difference $(p<0.05)$. These values are significantly lower (almost 10 -fold lower) than the TPC values for field-grown leaves of six cultivated blueberry cultivars, including 'Toro' (132.92 mg GAE/g leaves material), reported by Ștefănescu et al. [6]. In addition, Wu et al. [11] also reported significantly higher TPC values for blueberry field-grown leaves from 73 different cultivars collected in southern China, which ranged from $32.18 \pm 0.01$ ('O'Neal') to $224.1 \pm 3.4$ ('Blackpearl') mg GAE/g DW. Moreover, the same study determined TPC values in the leaves of field-grown 'Toro' plants of $75.07 \pm 1.48 \mathrm{mg}$ GAE/g 
DW, which is 5.3- and 5.6-fold higher than the TPC values obtained in this study for both field-grown and in vitro leaves for the same cultivar, respectively. Goyali et al. [39] also obtained higher TPC values for the leaves of wild lowbush blueberry clone QB9C (Vaccinium angustifolium Ait.) originating from both ex vitro (propagation by stem cuttings) and in vitro propagated plants. These differences are mainly due to the differences in extract solvents. Namely, in this study the methanol extracts of leaves and calluses were evaporated, resuspended in milliQ water and, after filtration through $0.45 \mu \mathrm{m}$ syringe filters, subjected to spectrophotometric analysis, whereas the aforementioned authors used $40 \%$ ethanol, $85 \%$ methanol or $80 \%$ acetone. Furthermore, differences in method of extraction (solid-liquid against ultrasound-assisted extraction), applied in vitro propagation methods as well as the different geographical areas where the berry plant is grown, climatic factors and soil composition for field-grown plants can also affect the TPC value of analyzed samples $[4,5,36]$. Furthermore, total phenolics for both aqueous extracts, field-grown and in vitro leaves of 'Toro' blueberry were significantly higher $(p<0.05)$, in comparison to those of field-grown and in vitro leaves of 'Čačanska Bestrna', whose TPC values were $11.46 \pm 0.27$ and $8.97 \pm 0.35 \mathrm{mg} \mathrm{GAE} / \mathrm{g}$ DW, respectively. These values are significantly lower than previously reported TPC value for field-grown leaves of the same blackberry cultivar, also collected in Serbia [5]. However, the TPC value of field-grown blackberry leaves obtained in this study was significantly higher than the TPC values obtained for water extracts from the leaves of wild-grown and cultivated blackberry (Rubus fruticosus L. 'Thornfree') collected during different seasons of the year [40]. In the study conducted by Fathy et al. [20], TPC values for methanolic extracts obtained from the leaves of in vitro blackberry (Rubus fruticosus L.) shoots grown on media with different concentrations of PGRs (benzyladenine (BA) at different concentrations, applied alone or in combination with $\alpha$-naphthaleneacetic acid (NAA)), were in the range from 1.17 to $2.39 \mathrm{mg} \mathrm{GAE} / \mathrm{g}$, which is significantly less than the TPC value obtained for in vitro blackberry leaves in this study. Thus, PGR combinations applied to in vitro cultivation of blackberry 'Čačanska Bestrna' should be considered as promising, because in vitro leaves can be a good source of phenolic compounds for further applications in the food industry and pharmacy. As can be seen in Figure 2a, callus culture induced from both berry plants had significantly lower TPC in comparison with their leaves; the values were $1.52 \pm 0.03$ and $0.78 \pm 0.03 \mathrm{mg} \mathrm{GAE} / \mathrm{g}$ DW in blueberry 'Toro' and blackberry 'Čačanska Bestrna', respectively. The TPC value of blueberry callus culture was significantly lower than those reported by Ramata-Stunda et al. [31], and significantly higher than TPC values reported by Ghosh et al. [30] in callus culture of different blueberry cultivars. The TPC value of blackberry callus culture in this study was in agreement with the TPC values obtained for callus culture induced from blackberry (Rubus fruticosus L.) leaves treated with different concentrations of NAA and/or 2,4-dichlorophenoxyacetic acid (2,4-D) [20].

The total flavonoid content of aqueous extracts of 'Toro' and 'Čačanska Bestrna' leaves and their callus cultures are illustrated in Figure $2 \mathrm{~b}$. TFC values of aqueous extracts of field-grown and in vitro blueberry leaves were $18.56 \pm 0.98$ and $10.88 \pm 0.66 \mathrm{mg} \mathrm{CE} / \mathrm{g}$ DW, respectively. On the other hand, the TFC values of aqueous extracts of field-grown and in vitro leaves in blackberry were significantly lower (almost five-fold) in comparison with corresponding blueberry samples, i.e., $4.42 \pm 0.11$ and $2.44 \pm 0.34 \mathrm{mg} \mathrm{CE} / \mathrm{g} \mathrm{DW}$, respectively. Interestingly, the TFC value in the extract of field-grown blueberry leaves was significantly higher in comparison to the TPC value of the same extract, which was also observed in the study reported by Wu et al. [11]. TFC values in field-grown leaves of blueberry 'Toro' previously reported by Ștefănescu et al. [6] and Wu et al. [11], showed significantly higher flavonoid content in comparison to the value obtained in this study. As shown in Figure 2b, callus culture for both berry plants had significantly lower TFC values in comparison to the results obtained for their leaves, which is in accordance with the obtained results for TPC. The TFC values of blueberry and blackberry callus cultures $(1.31 \pm 0.03$ and $0.57 \pm 0.01 \mathrm{mg} \mathrm{CE} / \mathrm{g} \mathrm{DW}$, respectively) were not significantly different $(p<0.05)$. The literature survey led us to the conclusion that the data on the TFC 
of blueberry and blackberry callus culture are rather scarce. Ghosh et al. [30] obtained considerably higher TFC values for the callus culture of different blueberry cultivars, in comparison with TFC value obtained for 'Toro' blueberry callus culture in this study. On the other hand, Fathy et al. [20] obtained very low TFC values for methanolic extract of the callus culture induced from blackberry leaves which were treated with different concentrations and combinations of PGRs, such as 2,4-D and NAA.

\subsection{UHPLC-DAD MS/MS Analysis of Blueberry and Blackberry Leaves and Callus Cultures}

Characterization and quantification of phenolic compounds from aqueous extracts of blueberry and blackberry leaves, as well as their callus cultures, were performed using UHPLC-DAD MS/MS analyzer (Table 3).

Depending on the berry plant genotype and specific characteristics of samples tested, a total of 20 phenolic compounds was confirmed and quantified. As can be observed from Table 3, field-grown and in vitro leaves of blueberry 'Toro' are better source of phenolic compounds in comparison to field-grown and in vitro leaves of blackberry 'Čačanska Bestrna'. The most abundant PCs of 'Toro' leaves belong to phenolic acids, flavonols and flavan-3-ols, with respective shares of $41.3,54.3$, and $4.3 \%$ for field-grown, and $29.7,54.6$, and $14.9 \%$ for in vitro leaves. The dominant presence of phenolic acids and flavonols has been shown in some previous PC characterizations of leaves of different blueberry cultivars using the chromatographic technique [6,10-12]. Quercetin derivatives, chlorogenic acid and gallocatechin were dominant the PCs for both field-grown and in vitro blueberry leaves. Other studies have also reported quercetin derivatives $[6,11]$ and chlorogenic acid $[4,12,31]$ as the most abundant PCs in the leaves of various blueberry cultivars, including 'Toro'. Among quercetin derivatives, quercetin-3-O-glucoside and quercetin-3-O-rutinoside were the most predominant, with respective contents of $160.113 \pm 3.059$ and $49.639 \pm 1.526 \mathrm{mg} / \mathrm{kg}$ DW for extracts of field-grown leaves and $115.598 \pm 5.041$ and $62.293 \pm 4.403 \mathrm{mg} / \mathrm{kg}$ DW for extracts of in vitro leaves. This is in agreement with the result reported by Ștefănescu et al. [6] for field-grown leaf extract of various blueberry cultivars, including 'Toro'. Interestingly, significant amounts of flavonols, such as quercetin-3-O-rhamnoside, aesculetin, and the aglycones of quercetin and kaempferol, have been identified only in extracts of in vitro blueberry leaves.

On the other hand, the quercetin derivatives syringic and chlorogenic acid were the most abundant phenolic compounds detected in field-grown and in vitro leaves of blackberry 'Čačanska Bestrna', making more than $95 \%$ of all quantified phenolics. Some previous studies have reported significantly higher contents of different phenolic acids and flavonoids in methanolic extracts of field-grown leaves of three blackberry wild genotypes and three cultivars [7], or 26 different wild blackberry genotypes collected from various localities throughout Poland [9]. Flavan-3-ols were not detected in the leaves of 'Čačanska Bestrna', which is not in accordance with the results reported by Pavlović et al. [5], which found significant amounts of catechin derivatives in methanolic extract of field-grown leaves of the same blackberry cultivar, also collected in Serbia. The absence of flavan-3-ols can be attributed to their ability to rapidly polymerize in aqueous extract into complex forms, which were removed by filtration through a $0.45 \mu \mathrm{m}$ filter before UHPLC-DAD MS/MS analysis. Differences in the phenolic profiles of leaves originating from in vitro cultivated plants may be due to applied PGRs [17] such as zeatin and indol-3-acetic acid for blueberry 'Toro'; that is, gibberellic acid $\left(\mathrm{GA}_{3}\right), \mathrm{BA}$ and indole-3-butyric acid (IBA) for blackberry 'Čačanska Bestrna' (Table 1). 
Table 3. The content of phenolic compounds in field-grown and in vitro leaves, as well as in callus cultures of blueberry and blackberry.

\begin{tabular}{|c|c|c|c|c|c|c|}
\hline \multirow{2}{*}{ Samples } & \multicolumn{3}{|c|}{ Blueberry 'Toro' } & \multicolumn{3}{|c|}{ Blackberry 'Čačanska Bestrna' } \\
\hline & Field-Grown Leaves & In Vitro Leaves & Callus Culture & Field-Grown Leaves & In Vitro Leaves & Callus Culture \\
\hline \multicolumn{7}{|l|}{ Phenolics (mg/kg) } \\
\hline & \multicolumn{6}{|c|}{ Phenolic acids } \\
\hline Gallic acid & / & / & / & / & / & $0.202 \pm 0.005$ \\
\hline Vanillic acid & / & / & $0.136 \pm 0.009$ & / & / & / \\
\hline Ferulic acid & / & / & $0.330 \pm 0.021^{b}$ & / & / & $0.154 \pm 0.017^{\mathrm{c}}$ \\
\hline Syringic acid & / & / & / & $11.348 \pm 1.125^{\mathrm{a}}$ & $6.701 \pm 0.243^{b}$ & / \\
\hline Chlorogenic acid & $162.817 \pm 11.251^{b}$ & $111.826 \pm 3.174^{\mathrm{c}}$ & / & $9.484 \pm 0.591^{\mathrm{d}}$ & $2.922 \pm 0.041^{\mathrm{e}}$ & / \\
\hline \multirow[t]{2}{*}{ Sum } & $162.817(41.3)$ & $111.826(29.7)$ & 0.466 & $20.832(56.4)$ & $9.623(73.6)$ & 0.356 \\
\hline & \multicolumn{6}{|c|}{ Flavan-3-ols } \\
\hline Catechin & / & / & $0.567 \pm 0.045^{b}$ & / & / & / \\
\hline Catechin gallate & / & / & $0.051 \pm 0.004^{\mathrm{b}}$ & / & / & $0.048 \pm 0.002^{b}$ \\
\hline Gallocatechin & $17.077 \pm 1.078^{\mathrm{a}}$ & $56.239 \pm 2.816^{b}$ & / & / & / & / \\
\hline \multirow[t]{2}{*}{ Sum } & $17.077(4.3)$ & $56.239(14.9)$ & 0.618 & I & l & 0.048 \\
\hline & \multicolumn{6}{|c|}{ Flavonols } \\
\hline Quercetin & / & $17.304 \pm 1.315$ & / & / & / & / \\
\hline Quercetin-3-O-rutinoside & $49.639 \pm 1.526^{\mathrm{c}}$ & $62.293 \pm 4.403^{\mathrm{d}}$ & $0.085 \pm 0.006^{\mathrm{b}}$ & $7.395 \pm 0.197^{\mathrm{e}}$ & $1.061 \pm 0.079^{\mathrm{f}}$ & / \\
\hline Quercetin-3-O-rhamnoside & / & $6.533 \pm 0.528$ & / & / & / & / \\
\hline Isohramnetin-3-O-rutinoside & / & / & $0.034 \pm 0.001$ & / & / & / \\
\hline Isohramnetin-3-O-glucoside & / & / & $0.093 \pm 0.003$ & / & / & / \\
\hline Kaempferol-3-O-glucoside & $4.538 \pm 0.207^{b}$ & $2.598 \pm 0.249^{c}$ & / & $2.540 \pm 0.100^{c}$ & $0.154 \pm 0.015^{\mathrm{d}}$ & / \\
\hline Kaempferol & / & $1.435 \pm 0.036$ & / & 1 & / & / \\
\hline Apigenin-7-O-glucoside & / & / & 1 & $0.284 \pm 0.027$ & / & / \\
\hline \multirow[t]{2}{*}{ Sum } & $214.29(54.3)$ & $205.761(54.6)$ & 0.601 & $15.702(42.3)$ & $2.912(22.3)$ & 0.183 \\
\hline & \multicolumn{6}{|c|}{ Other detected phenols } \\
\hline Naringenin & $0.361 \pm 0.028$ & / & / & / & / & / \\
\hline Aesculetin & / & $2.848 \pm 0.181^{\mathrm{a}}$ & / & $0.432 \pm 0.024^{b}$ & $0.530 \pm 0.028^{c}$ & / \\
\hline Phlorizin & / & / & $0.068 \pm 0.003^{\mathrm{a}}$ & / & / & $0.058 \pm 0.004^{b}$ \\
\hline Sum & 0.361 & 2.848 & 0.068 & 0.432 & 0.530 & 0.058 \\
\hline Total & 394.545 & 376.674 & 1.753 & 36.965 & 13.065 & 0.645 \\
\hline
\end{tabular}

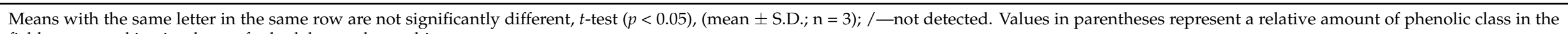
field-grown and in vitro leaves for both berry plant cultivars. 
Generally, the field-grown and in vitro blueberry/blackberry leaves have shown to be a much better source of phenolic compounds (PCs) in comparison to in vitro induced callus culture obtained from in vitro leaves of the same berry cultivars. The low yield of phenolic compounds in the callus culture of blueberry 'Toro' and blackberry 'Čačanska Bestrna' can be explained by the lack of cell differentiation [15]. The callus culture of 'Toro' produced higher levels of specific phenolic acids, flavan-3-ols and flavonols, in comparison with the callus culture of 'Čačanska Bestrna'. However, both aqueous extract of blueberry and blackberry callus cultures contained small amounts of individually detected PCs. Interestingly, except for quercetin-3-O-glucoside and quercetin-3-O-rutinoside, other identified phenolics are specific for blueberry callus culture and have not been detected in field-grown and in vitro blueberry leaf extracts. For example, small amounts of phenolic acid such as vanillic and ferulic acid $(0.330 \pm 0.021 \mathrm{mg} / \mathrm{kg} \mathrm{DW})$, or flavan-3-ols such as catechin $(0.567 \pm 0.045 \mathrm{mg} / \mathrm{kg} \mathrm{DW})$ and catechingallate, were found in the callus extract of 'Toro', while chlorogenic acid and gallocatechin were not detected. However, in the study of Ramata-Stunda et al. [31], chlorogenic acid was the most abundant PC in the callus culture of 'Duke' and 'Bluecrop' blueberries, while other phenolic acids were present in traces. This may be due to the presence of phytohormones and elicitors in nutrient medium, which are able to initiate the synthesis of specific PCs $[16,17]$. On the other hand, although in small amounts, quercetin-3-O-glucoside, gallic and ferulic acid were found as dominant PCs in the callus culture of blackberry 'Čačanska Bestrna', while other phenolics were detected in traces. Interestingly, the predominantly confirmed syringic and chlorogenic acids in field-grown and in vitro blackberry leaf extracts were not found in the callus culture of this berry plant, but gallic and ferulic acid were. However, the effect of different PGRs on the synthesis of specific PCs in the callus cultures of 'Toro' and 'Čačanska Bestrna' requires a more complex experiment and additional research.

\subsection{Antioxidant Properties}

Using different in vitro screening assays for evaluating the antioxidant properties of prepared aqueous extracts of field-grown leaves, in vitro leaves and callus cultures of blackberry and blueberry gives better insight into their potential opportunities for health improvement and further applications. In order to obtain more detailed information on the antioxidant properties of the analyzed samples, it is very important to apply several different tests based on different mechanisms of action. Three mechanisms of action of bioactive compounds are generally known: hydrogen atom transfer (HAT), single electron transfer (SET), and the ability to chelate transition metals [41-43]. These mechanisms include several tests most commonly used to assess the antioxidant properties of phenolics extracts of leaves and callus cultures of berry plants $[11,12,20,31,44]$. In this study, three in vitro screening antioxidant assays, $\mathrm{FRP}, \mathrm{ABTS}^{\bullet+}$ and $\mathrm{DPPH}{ }^{\bullet}$ scavenging activity, were used with the aim of evaluating the antioxidant potential of the leaves and calluses of blueberry and blackberry cultivars (Figure 3).

According to our knowledge, this is the first time the antioxidant properties of in vitro leaves and calluses of these berry plant cultivars has been evaluated by performing these three assays. 
(a)

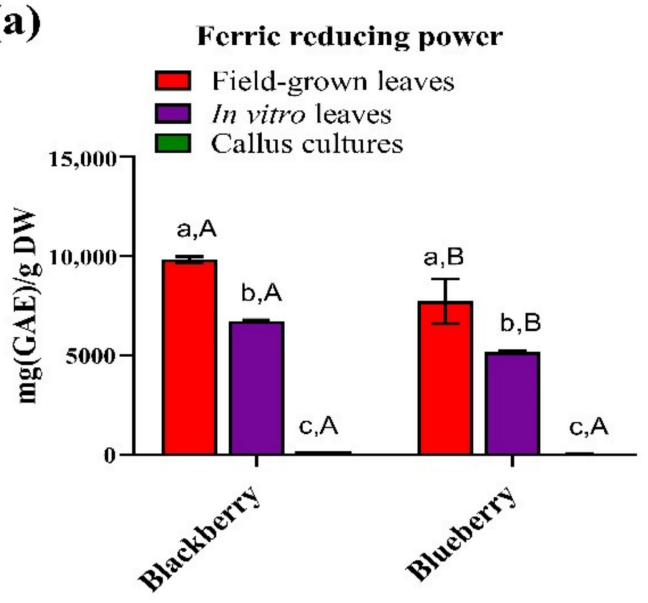

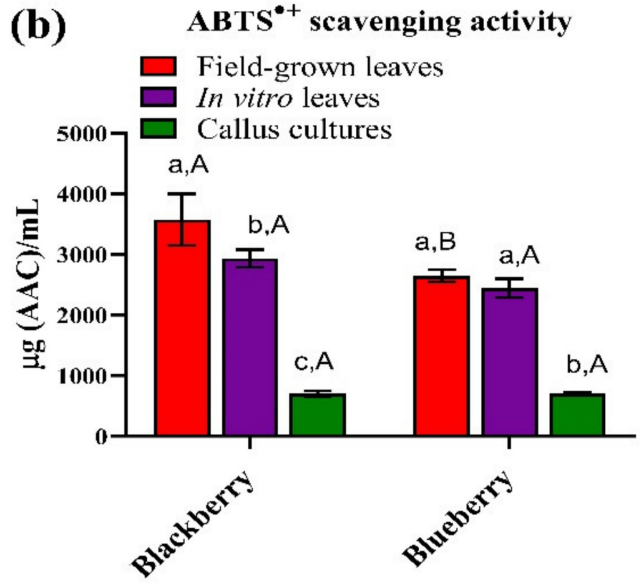

(c)

DPPH$^{\bullet}$ scavenging activity

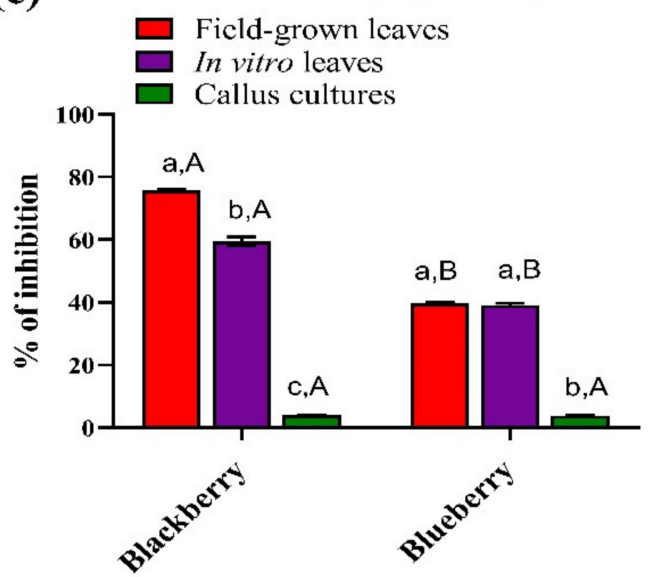

Figure 3. (a) Ferric reducing power (FRP), (b) $\mathrm{ABTS}^{\bullet+}$ radical scavenging activity, and (c) $\mathrm{DPPH}^{\bullet}$ radical scavenging activity of field-grown leaves, in vitro leaves and callus cultures of blackberry 'Čačanska Bestrna' and blueberry 'Toro'. The bars with $( \pm)$ standard deviation represent mean values. The different lowercase letters indicate a significant difference $(p<0.05)$ between field-grown leaves, in vitro leaves and callus culture of the same berry. Different uppercase letters indicate a significant difference $(p<0.05)$ between the same types of samples of two different cultivars.

\subsection{Ferric Reducing Power (FRP)}

The Ferric reducing antioxidant power (FRAP) assay was most commonly used in the literature to assess the reducing properties of extracts of blueberry $[11,12]$ and blackberry $[9,40]$ leaves. However, this assay has some limitations, such as the low $\mathrm{pH}$ value applied and the reactivity rate of different types of molecules, giving variable results [42]. On the other hand, the ferric reducing power assay is based on the ability of bioactive compounds to reduce $\mathrm{Fe}^{3+}$-ferricyanide complexes to their ferrous $\left(\mathrm{Fe}^{2+}\right)$ form in more relevant physiological conditions $(\mathrm{pH}=6.6)$ [42], and can serve as a significant indicator of antioxidant activity of prepared leaves and callus culture extracts of blueberry and blackberry.

The aqueous extracts of field-grown and in vitro leaves of blueberry 'Toro' and blackberry 'Čačanska Bestrna' analyzed in this study showed good ferric reducing ability (Figure 3a). More precisely, the FRP values for field-grown leaves were $7722.75 \pm 1125.62$ ('Toro') and $9815.27 \pm 155.52$ ('Čačanska Bestrna') mg GAE/g DW, while for in vitro leaves the values were $5153.76 \pm 88.37$ and $6731.56 \pm 50.96 \mathrm{mg}$ GAE/g DW, respectively. As can be seen in Figure 3a, the FRP values of field-grown leaves for both berry plants leaves were significantly higher $(p<0.05)$ in comparison with the FRP values of in vitro leaves, which 
is in agreement with TPC and TFC results. Good ferric reducing ability of field-grown blackberry and blueberry leaves has also been reported by other authors $[9,11,12]$. However, a direct comparison is not possible, primarily due to the previously mentioned FRAP method used by the authors to measure the reducing ability of leaf extracts. Interestingly, field-grown and in vitro leaves of blackberry 'Čačanska Bestrna' had better FRP activity than field-grown and in vitro leaves of blueberry 'Toro' (Figure 3a). This contrasts with the results obtained by chromatographic, TPC and TFC analysis, which showed a more diverse and higher content of phenolic compounds in the leaves of 'Toro'. This can be explained by the fact that field-grown and in vitro leaf extracts of blackberry contain other highly effective antioxidants in addition to the quantified phenolic compounds, such as ellagic acid derivatives, ellagitannins [5,9], vitamin C [45] and some terpenes [46] in significant quantities, which have not been analyzed in this study. On the other hand, aqueous extracts of callus cultures in both berry plants showed very low ferric reducing ability, which is consistent with the results obtained for their individual and total phenolic content. Correlation analysis revealed a significant positive correlation $(p<0.05)$ between FRP and $\operatorname{TPC}(r=0.87)$.

\subsection{ABTS $^{\bullet+}$ and $D P P H^{\bullet}$ Scavenging Activity}

The ABTS ${ }^{\bullet+}$ scavenging activity of aqueous extracts of field-grown leaves of blackberry 'Čačanska Bestrna' was $3574.10 \pm 426.78 \mu \mathrm{gAAC} / \mathrm{mL}$, which was significantly higher than $\mathrm{ABTS}^{\bullet+}$ values for aqueous extracts of in vitro leaves of the same culti$\operatorname{var}(2933.51 \pm 147.84 \mu \mathrm{gAAC} / \mathrm{mL})$ or field-grown and in vitro leaves of blueberry 'Toro' (Figure $3 \mathrm{~b}$ ). $\mathrm{ABTS}^{\bullet+}$ scavenging activity of aqueous extracts of field-grown and in vitro leaves of blueberry were $2644.22 \pm 98.43$ and $2442.74 \pm 155.24 \mu \mathrm{gAAC} / \mathrm{mL}$, without significant differences. As with the FRP results, aqueous extracts of field-grown and in vitro leaves of blackberry showed $\mathrm{ABTS}^{\bullet+}$ values significantly higher than $\mathrm{ABTS}^{\bullet+}$ values for aqueous extracts of field-grown and in vitro leaves of blueberry. This is not in accordance with the chromatographic and spectrophotometrically obtained results for individual and total phenolics, which are significantly higher for blueberry 'Toro'. A previous study by Pavlović et al. [5] using UHPLC-LTQ OrbiTrap MS/MS analysis showed that the leaves of 'Čačanska Bestrna' blackberry predominantly contain ellagic acid and its derivatives, as well as ellagitannins, which probably contribute to the high $\mathrm{ABTS}^{\bullet+}$ values. Due to the large number of hydroxyl groups, ellagic acid and its derivatives, as well as ellagitannins, are potentially good hydrogen ion donors and scavengers of $\mathrm{ABTS}^{\bullet+}$. Other authors have also noticed good $\mathrm{ABTS}^{\bullet+}$ scavenging activity by different leaves of wild blackberry [9] and blueberry cultivars, including 'Toro' [11,12], but a direct comparison with our results is not possible due to differences in measurement units and the applied methods. The ABTS ${ }^{\bullet+}$ scavenging activity of callus cultures were $701.48 \pm 18.27$ ('Toro') and $703.14 \pm 46.50$ ('Čačanska Bestrna') $\mu \mathrm{gAAC} / \mathrm{mL}$, without significant difference $(p<0.05)$ (Figure 3b). The obtained $\mathrm{ABTS}^{\bullet+}$ values for callus cultures are about three-fold (blueberry), that is, about four-fold (blackberry) less than the ABTS ${ }^{\bullet+}$ values obtained for field-grown and in vitro leaves of the same berry plants. To the best of our knowledge, this is the first time that the $\mathrm{ABTS}^{\bullet+}$ scavenging activity of in vitro leaves and callus cultures of blueberry and blackberry has been determined.

The $\mathrm{DPPH}^{\bullet}$ scavenging assay is most commonly used to evaluate the antioxidant properties of field-grown leaves $[5,6,38,39,44]$ and callus cultures $[30,31]$ of different blueberry and blackberry cultivars. In this study, similar to the FRP results, aqueous extracts of field-grown and in vitro leaves of blackberry 'Čačanska Bestrna' showed ABTS ${ }^{\bullet+}$ values significantly higher than $\mathrm{ABTS}^{\bullet+}$ values for aqueous extracts of field-grown and in vitro leaves of blueberry 'Toro'. This is not in compliance with the chromatographic and spectrophotometrically obtained results for individual and total phenolics, which are significantly higher for blueberry. A previous study by Pavlović et al. [5], using UHPLC-LTQ OrbiTrap MS/MS analysis showed that the leaves of 'Čačanska Bestrna' blackberry predominantly contain ellagic acid and its derivatives, as well as ellagitannins, which probably contribute to high 
$\mathrm{ABTS}^{\bullet+}$ values. Due to a large number of hydroxyl groups, ellagic acid, its derivatives, and ellagitannins are potentially good hydrogen ion donors and scavengers of $\mathrm{ABTS}^{\bullet+}$. Other authors have also noticed good $\mathrm{ABTS}^{\bullet+}$ scavenging activity of different leaves of wild blackberry [9] and blueberry cultivars, including 'Toro' [11,12], but a direct comparison with our results is not possible due to differences in measurement units and the applied methods. The ABTS ${ }^{\bullet+}$ scavenging activity of callus cultures were $701.48 \pm 18.27$ ('Toro') and $703.14 \pm 46.50$ ('Čačanska Bestrna') $\mu \mathrm{g} \mathrm{AAC} / \mathrm{mL}$, respectively, without significant differences $(p<0.05)$ (Figure $3 b)$. The obtained ABTS ${ }^{\bullet+}$ values for callus cultures are about three-fold (blueberry), that is, about five-fold (blackberry) less than the ABTS ${ }^{\bullet+}$ values obtained for field-grown and in vitro leaves of the same berry plant. As far as we know, this is the first time that the $\mathrm{ABTS}^{\bullet+}$ scavenging activity of in vitro leaves and callus cultures of blueberry and blackberry cultivars has been determined. Aqueous extracts of field-grown and in vitro leaves of blackberry ‘Čačanska Bestrna' showed significantly higher percentage of inhibition of DPPH radicals (75.77\% and $59.44 \%$, respectively), than field grown $(39.15 \%$ ) and in vitro (39.65\%) leaves of blueberry 'Toro' (Figure 3c). These DPPH' results show the same trend as the results obtained for the $\mathrm{ABTS}^{\bullet+}$ scavenging activity and FRP assays. Correlation analysis revealed a significant positive correlation $(p<0.05)$ between the FRP and $\mathrm{ABTS}^{\bullet+}(r=0.98)$ and $\mathrm{DPPH}^{\bullet}(r=0.95)$ scavenging activities, indicating that aqueous extracts of investigated samples that showed good ferric reducing power also possessed a good ability to scavenge free radicals.

However, the radical scavenging assays are also not consistent with the results obtained for individual and total phenolics analyzed in this study. The activity of complex extracts according to $\mathrm{DPPH}^{\bullet}$ is different and closely dependent on the nature of the phenolic compounds present in the extract, because $\mathrm{DPPH}^{\bullet}$ is known as a stable and lipophilic radical [47]. Good $\mathrm{DPPH}^{\bullet}$ scavenging activity has been previously reported for methanolic and aqueous extracts of field-grown leaves in various blackberry cultivars [38] and methanolic extracts of 'Čačanska Bestrna' leaves also collected in Serbia (83.77\%) [5]. Furthermore, several studies have shown good DPPH ${ }^{\bullet}$ scavenging activity for extracts of field-grown leaves of various blueberry cultivars, including leaves of 'Toro' $[6,11,12]$. Callus cultures of both berry cultivars had significantly lower $\mathrm{DPPH}^{\bullet}$ scavenging activity, that is, $3.89 \%$ ('Toro') and $4.01 \%$ ('Čačanska Bestrna').

Based on the obtained results of the three antioxidant assays, aqueous extracts of fieldgrown leaves of blackberry 'Čačanska Bestrna' showed the best antioxidant properties, while aqueous callus culture extracts of both berry cultivars had the lowest phenolic content and significantly lower antioxidant properties than the corresponding leaves.

\section{Conclusions}

This study demonstrated that the aqueous extracts of field-grown and in vitro leaves of blueberry 'Toro' are a better source of total phenolics and flavonoids than those of blackberry 'Čačanska Bestrna', with the former having ten to almost thirty times higher content of PCs as determined by the UHPLC-DAD MS/MS technique. Low TPC and TFC values for both callus cultures were obtained. A total of 20 phenolic compounds were found in all analyzed samples. Quercetin derivatives, chlorogenic acid and gallocatechin were the dominant PCs for both field-grown and in vitro blueberry leaves, whereas quercetin derivatives, syringic and chlorogenic acid were the most abundant phenolic compounds in blackberry. Significant amounts of flavonols such as quercetin-3-O-rhamnoside, aesculetin and the aglycones of quercetin and kaempferol were identified only in the in vitro blueberry leaf extract, whereas the phenolic compound profiles of field-grown and in vitro leaves of blackberry were very similar. On the other hand, callus cultures of both berry cultivars had a significantly different PC profile compared to the corresponding leaves.

This study, for the first time, reported the antioxidant properties of in vitro leaves and calluses of these two berry cultivars by the FRP, ABTS ${ }^{\bullet+}$ and $\mathrm{DPPH}^{\bullet}$ scavenging activities. Opposite to the results of the PC analysis, field-grown and in vitro leaves of blackberry 'Čačanska Bestrna' had better FRP activity, $\mathrm{ABTS}^{\bullet+}$ and $\mathrm{DPPH}^{\bullet}$ scavenging activities than 
field-grown and in vitro leaves of blueberry 'Toro', except for $\mathrm{ABTS}^{\bullet}$ scavenging activity of in vitro leaves, which did not differ between cultivars. Callus cultures of both berry cultivars showed significantly lower antioxidant activities than the corresponding leaves.

In summary, the aqueous extracts of field-grown and in vitro leaves of blackberry 'Čačanska Bestrna' and blueberry 'Toro' can be a good source of phenolic compounds and exhibit good antioxidant properties, whereas callus cultures of both cultivars can have potential for the production of specific phenolic compounds.

Supplementary Materials: The following are available online at https:/ / www.mdpi.com/article/10 .3390/horticulturae7110420/s1, Table S1: Composition of Murashige and Skoog (MS) basal medium; Table S2: The list of quantified phenolic compounds, with retention times ( $\mathrm{min}$ ), SRM transitions and specified collision energies; Figure S1: Axillary shoot proliferation of blackberry 'Čačanska Bestrna'; Figure S2. Axillary shoot proliferation of blueberry 'Toro'.

Author Contributions: Conceptualization, T.K., T.V., R.C., D.D.M. and M.B.P.; methodology, D.D.M., A.Ž.K. and M.B.P.; software, D.D.M.; validation, U.M.G.; formal analysis, T.K., D.D.M., T.V., L.P., A.Ž.K., S.P.S. and U.M.G.; investigation, T.K., D.D.M., A.Ž.K. and M.B.P.; data curation, D.D.M. and M.B.P.; writing—original draft preparation, D.D.M.; writing—review and editing, M.B.P., T.V. and R.C.; supervision, T.V., L.P., R.C. and Ž.L.T.; project administration, M.B.P. All authors have read and agreed to the published version of the manuscript.

Funding: This research was funded by the Ministry of Education, Science and Technological Development of the Republic of Serbia, grant numbers: 451-03-9/2021-14/200116, 451-03-9/2021-14/200287, 451-03-9/2021-14/200215, 451-03-9/2021-14/200168 and 451-03-9/2021-14/200007.

Institutional Review Board Statement: Not applicable.

Informed Consent Statement: Not applicable.

Data Availability Statement: Not applicable.

Conflicts of Interest: The authors declare no conflict of interest.

\begin{abstract}
Abbreviations
BA-N6-benzyladenine; 2,4-D—2,4-dichlorophenoxyacetic acid; $\mathrm{GA}_{3}$ - gibberellic acid; IAA-Indole3-acetic acid; IBA—indole-3-butyric acid; MS—Murashige and Skoog (1962) medium; NAA— $\alpha$ Naphthaleneacetic acid; PCs—phenolic compunds; TPC—-total phenolic content; TFC—-total flavonoid content; FRP—-ferric reducing power.
\end{abstract}

\title{
References
}

1. Petrović, S.; Leposavić, A.; Veljković, B. Blackberry and Blueberry, Technology of Production and Processing, 1st ed.; Fruit Research Institute Čačak: Čačak, Serbia; Ljekobilje doo Trebinje: Trebinje, Bosnia and Herzegovina, 2007.

2. Diaconeasa, Z.; Florica, R.; Rugină, D.; Cuibus, L.; Socaciu, C. HPLC/PDA-ESI/MS Identification of Phenolic acids, flavonol glycosides and antioxidant potential in blueberry, blackberry, raspberries and cranberries. J. Food Nutr. Res. 2014, 2, 781-785. [CrossRef]

3. Sellappan, S.; Akoh, C.C.; Krewer, G. Phenolic compounds and antioxidant capacity of Georgia-grown blueberries and blackberries. J. Agric. Food Chem. 2002, 50, 2432-2438. [CrossRef]

4. Ferlemi, A.V.; Lamari, F.N. Berry leaves: An alternative source of bioactive natural products of nutritional and medicinal value. Antioxidants 2016, 5, 17. [CrossRef]

5. Pavlović, A.V.; Papetti, A.; Zagorac, D.Č.D.; Gašić, U.M.; Mišić, D.M.; Tešić, Ž.L.; Natić, M.M. Phenolics composition of leaf extracts of raspberry and blackberry cultivars grown in Serbia. Ind. Crops Prod. 2016, 87, 304-314. [CrossRef]

6. Ștefănescu, B.-E.; Călinoiu, L.F.; Ranga, F.; Fetea, F.; Mocan, A.; Vodnar, D.C.; Crișan, G. The chemical and biological profiles of leaves from commercial blueberry varieties. Plants 2020, 9, 1193. [CrossRef]

7. Gudej, J.; Tomczyk, M. Determination of flavonoids, tannins and ellagic acid in leaves from Rubus L. species. Arch. Pharm. Res. 2004, 27, 1114-1119. [CrossRef] [PubMed]

8. Oszmiański, J.; Wojdyło, A.; Gorzelany, J.; Kapusta, I. Identification and characterization of low molecular weight polyphenols in berry leaf extracts by HPLC-DAD and LC-ESI/MS. J. Agric. Food Chem. 2011, 59, 12830-12835. [CrossRef] [PubMed]

9. Oszmiański, J.; Wojdyło, A.; Nowicka, P.; Teleszko, M.; Cebulak, T.; Wolanin, M. Determination of phenolic compounds and antioxidant activity in leaves from wild Rubus L. species. Molecules 2015, 20, 4951-4966. [CrossRef] [PubMed] 
10. Riihinen, K.; Jaakola, L.; Kärenlampi, S.; Hohtola, A. Organ-specific distribution of phenolic compounds in bilberry (Vaccinium myrtillus) and 'Northblue' blueberry (Vaccinium corymbosum x V. angustifolium). Food Chem. 2008, 110, 156-160. [CrossRef] [PubMed]

11. Wu, H.; Chai, Z.; Hutabarat, R.P.; Zeng, Q.; Niu, L.; Li, D.; Yu, H.; Huang, W. Blueberry leaves from 73 different cultivars in southeastern China as nutraceutical supplements rich in antioxidants. Food Res. Int. 2019, 122, 548-560. [CrossRef]

12. Wang, L.-J.; Wu, J.; Wang, H.-X.; Li, S.-S.; Zheng, X.-C.; Du, H.; Xu, Y.-J.; Wang, L. Composition of phenolic compounds and antioxidant activity in the leaves of blueberry cultivars. J. Funct. Foods 2015, 16, 295-304. [CrossRef]

13. Silva, S.; Costa, E.; Pereira, M.; Costa, M.R.; Pintado, M. Evaluation of the antimicrobial activity of aqueous extracts from dry Vaccinium corymbosum extracts upon food microorganism. Food Control 2013, 34, 645-650. [CrossRef]

14. Milinčić, D.D.; Vojinović, U.D.; Kostić, A.; Pešić, M.B.; Špirović Trifunović, B.D.; Brkić, D.V.; Stević, M.; Kojić, M.O.; Stanisavljević, N.S. In vitro assessment of pesticide residues bioaccessibility in conventionally grown blueberries as affected by complex food matrix. Chemosphere 2020, 252, 126568. [CrossRef]

15. Espinosa-Leal, C.; Puente-Garza, C.; García-Lara, S. In vitro plant tissue culture: Means for production of biological active compounds. Planta 2018, 248, 1-18. [CrossRef]

16. Matkowski, A. Plant in vitro culture for the production of antioxidants-A review. Biotechnol. Adv. 2008, 26, 548-560. [CrossRef]

17. Smetanska, I. Sustainable Production of polyphenols and antioxidants by plant in vitro cultures. In Bioprocessing of Plant In Vitro Systems; Pavlov, A., Bley, T., Eds.; Reference Series in Phytochemistry; Springer: Cham, Switzerland, 2018 ; pp. 1-45.

18. Weathers, P.J.; Towler, M.J.; Xu, J. Bench to batch: Advances in plant cell culture for producing useful products. Appl. Microbiol. Biotechnol. 2010, 85, 1339-1351. [CrossRef]

19. Dongliang, Q.; Xiangying, W.; Shufang, F.; Dawei, J.; Jianjun, C. Regeneration of blueberry cultivars through indirect shoot organogenesis. HortScience 2018, 53, 1045-1049.

20. Fathy, H.; El-Leel, O.; Amin, M.; AbuEl-Leel, O. Micropropagation and biomass production of Rubus fruticosus L. (blackberry) plant. MEJAS 2020, 8, 1-14.

21. Hunková, J.; Gajdošová, A.; Szabóová, M. Effect of mesos components(MgSO(4), $\mathrm{CaCl}(2), \mathrm{KH}(2) \mathrm{PO}(4))$ on in vitro shoot growth of blackberry, blueberry, and saskatoon. Plants 2020, 9, 935. [CrossRef]

22. Ružić, Đ.; Vujović, T.; Libiakova, G.; Cerović, R.; Gajdošova, A. Micropropagation in vitro of highbush blueberry (Vaccinium corymbosum L.). J. Berry Res. 2012, 2, 97-103. [CrossRef]

23. Vujović, T.; Ružić, D.; Cerović, R.; Leposavić, A.; Žaklina, K.-S.; Mitrović, O.; Žurawicz, E. An assessment of the genetic integrity of micropropagated raspberry and blackberry plants. Sci. Hortic. 2017, 225, 454-461. [CrossRef]

24. Ikeuchi, M.; Sugimoto, K.; Iwase, A. Plant callus: Mechanisms of induction and repression. Plant Cell 2013, 25, 3159-3173. [CrossRef] [PubMed]

25. Sák, M.; Dokupilová, I.; Mihálik, D.; Lakatošová, J.; Gubišová, M.; Kraic, J. Elicitation phenolic compounds in cell culture of Vitis vinifera L. by Phaeomoniella chlamydospora. Nova Biotechnol. Chim. 2015, 13, 162-171. [CrossRef]

26. Saw, N.M.M.T.; Riedel, H.; Cai, Z.; Kütük, O.; Smetanska, I. Stimulation of anthocyanin synthesis in grape (Vitis vinifera) cell cultures by pulsed electric fields and ethephon. Plant Cell Tissue Organ Cult. (PCTOC) 2012, 108, 47-54. [CrossRef]

27. Cai, Z.; Kastell, A.; Speiser, C.; Smetanska, I. Enhanced resveratrol production in Vitis vinifera cell suspension cultures by heavy metals without loss of cell viability. Appl. Biochem. Biotechnol. 2013, 171, 330-340. [CrossRef]

28. Bonello, M.; Gašić, U.; Tešić, Ž.; Attard, E. Production of stilbenes in callus cultures of the Maltese indigenous grapevine variety, Ġellewża. Molecules 2019, 24, 2112. [CrossRef]

29. Karaaslan, M.; Ozden, M.; Vardin, H.; Turkoglu, H. Phenolic fortification of yogurt using grape and callus extracts. LWT-Food Sci. Technol. 2011, 44, 1065-1072. [CrossRef]

30. Ghosh, A.; Igamberdiev, A.U.; Debnath, S.C. Thidiazuron-induced somatic embryogenesis and changes of antioxidant properties in tissue cultures of half-high blueberry plants. Sci. Rep. 2018, 8, 16978. [CrossRef]

31. Ramata-Stunda, A.; Valkovska, V.; Boroduske, A.; Silamikele, B.; Kaktina, E.; Rostoks, N.; Boroduškis, M.; Livkisa, D.; Pentjuss, A. Development of metabolic engineering approaches to regulate the content of total phenolics, antiradical activity and organic acids in callus cultures of the highbush blueberry (Vaccinium corymbosum L.). Agron. Res. 2020, 18, 1860-1872.

32. Eibl, R.; Meier, P.; Stutz, I.; Schildberger, D.; Hühn, T.; Eibl, D. Plant cell culture technology in the cosmetics and food industries: Current state and future trends. Appl. Microbiol. Biotechnol. 2018, 102, 8661-8675. [CrossRef]

33. Zydlik, Z.; Cieśliński, S.; Mai, V.C.; Kafkas, N.E.; Morkunas, I. Soil Preparation, Running Highbush Blueberry (Vaccinium corymbosum L.) Plantation and Biological Properties of Fruits. In Modern Fruit Industry; Kahramanoglu, I., Kafkas, N.E., Küden, A., Çömlekçioğlu, S., Eds.; IntechOpen: London, UK, 2019. Available online: https://www.intechopen.com/chapters/69082 (accessed on 28 September 2021.).

34. Murashige, T.; Skoog, F. A revised medium for rapid growth and bio assays with tobacco tissue cultures. Physiol. Plant. 2006, 15, 473-497. [CrossRef]

35. Pavlović, A.V.; Dabić, D.; Momirović, N.M.; Dojčinović, B.P.; Milojković-Opsenica, D.M.; Tešić, Z.; Natić, M.M. Chemical composition of two different extracts of berries harvested in Serbia. J. Agric. Food Chem. 2013, 61, 4188-4194. [CrossRef]

36. Singleton, V.L.; Orthofer, R.; Lamuela-Raventós, R. Analysis of total phenols and other oxidation substrates and antioxidants by means of Folin-Ciocalteu reagent. Meth. Enzymol. 1999, 299, 152-178. 
37. Pešić, M.B.; Milinčić, D.D.; Kostić, A.Ž.; Stanisavljević, N.S.; Vukotić, G.N.; Kojić, M.O.; Gašić, U.M.; Barać, M.B.; Stanojević, S.P.; Popović, D.A.; et al. In vitro digestion of meat- and cereal-based food matrix enriched with grape extracts: How are polyphenol composition, bioaccessibility and antioxidant activity affected? Food Chem. 2019, 284, 28-44. [CrossRef] [PubMed]

38. Gawron-Gzella, A.; Dudek-Makuch, M.; Matławska, I. Dpph Radical scavenging activity and phenolic compound content in different leaf extracts from selected blackberry species. Acta Biol. Crac. Ser. Bot. 2012, 54, 32-38. [CrossRef]

39. Goyali, J.C.; Igamberdiev, A.U.; Debnath, S.C. Morphology, phenolic content and antioxidant capacity of lowbush blueberry (Vaccinium angustifolium Ait.) plants as affected by in vitro and ex vitro propagation methods. Can. J. Plant. Sci. 2013, 93, 1001-1008. [CrossRef]

40. Noémi, K.; Éva, S.-B.; Enikő, P. Element Composition, total phenolics and antioxidant activity of wild and cultivated blackberry (Rubus fruticosus L.) fruits and leaves during the harvest time. Not. Bot. Horti Agrobot. Cluj-Napoca 2018, 46, 563-569.

41. Granato, D.; Shahidi, F.; Wrolstad, R.; Kilmartin, P.; Melton, L.D.; Hidalgo, F.J.; Miyashita, K.; Camp, J.V.; Alasalvar, C.; Ismail, A.B.; et al. Antioxidant activity, total phenolics and flavonoids contents: Should we ban in vitro screening methods? Food Chem. 2018, 264, 471-475. [CrossRef]

42. Gülçin, İ. Antioxidant activity of food constituents: An overview. Arch. Toxicol. 2012, 86, 345-391. [CrossRef] [PubMed]

43. Prior, R.L.; Wu, X.; Schaich, K. Standardized methods for the determination of antioxidant capacity and phenolics in foods and dietary supplements. J. Agric. Food Chem. 2005, 53, 4290-4302. [CrossRef] [PubMed]

44. Ziemlewska, A.; Zagórska-Dziok, M.; Nizioł-Łukaszewska, Z. Assessment of cytotoxicity and antioxidant properties of berry leaves as by-products with potential application in cosmetic and pharmaceutical products. Sci. Rep. 2021, 11, 3240. [CrossRef] [PubMed]

45. Verma, R.; Gangrade, T.; Punasiya, R.; Ghulaxe, C. Rubus fruticosus (blackberry) use as an herbal medicine. Pharmacogn. Rev. 2014, 8, 101-104. [CrossRef] [PubMed]

46. Abu-Shandi, K.; Alrawashdeh, A.; Al-Mazaideh, G.; Abu-Nameh, E.; Al-Amro, A.; Alsoufi, H.; Al-Ma'abreh, A.; Al-Dawdeyah, A. A novel strategy for the identification of the medicinal natural products in Rubus fruticosus plant by using GC/MS technique: A study on leaves, stems and roots of the plant. Adv. Anal. Chem. 2015, 5, 31-41.

47. Tabart, J.; Kevers, C.; Pincemail, J.; Defraigne, J.-O.; Dommes, J. Comparative antioxidant capacities of phenolic compounds measured by various tests. Food Chem. 2009, 113, 1226-1233. [CrossRef] 